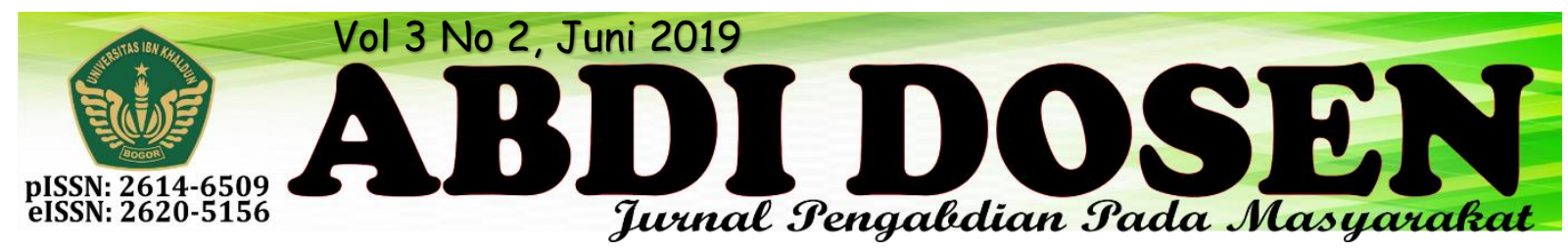

\title{
PENANGGULANGAN SAMPAH RUMAH TANGGA DAN POTENSI BAHAYA BANJIR DI LINGKUNGAN MASYARAKAT KAMPUNG CIASEUPAN DESA CIBITUNG KULON
}

\author{
Muhamad Lutfi ${ }^{1}$, Alif Farhan ${ }^{2}$, Nur Aisah Amini ${ }^{3}$ \\ $\underline{\text { mlutfi@ft.uika-bogor.ac.id }}^{1}$ \\ alif.farhan72@gmail.com ${ }^{2}$ \\ aisahamini13@gmail.com ${ }^{3}$
}

Fakultas Teknik Universitas Ibn Khaldun ${ }^{1}$, Mahasiswa KKN Kelompok 11 Tahun 2018 ${ }^{2,3}$

\begin{abstract}
ABSTRAK
Sampah merupakan salah satu bentuk konsekuensi dari adanya aktifitas dan volumenya akan sebanding lurus dengan jumlah penduduk. Apabila tidak di tangani secara efektif dan efisien, eksistensi sampah di alam tentu akan berbalik menghancurkan kehidupan di lingkungan sekitarnya baik itu berupa bencana seperti banjir maupun munculnya berbagai penyakit yang diakibatkan dari sampah tersebut. Perilaku yang tidak sehat berdampak pada perilaku masyarakat yang selalu membuang sampah sembarangan seperti di kali bahkan di parit sehingga timbunan sampah yang menumpuk di parit membuat terjadinya banjir ketika musim hujan. Kesadaran masyarakat terhadap sampah sangatlah berperan demi terciptanya lingkungan yang bersih dan sehat. Menyadarkan masyarakat terhadap perilaku membuang sampah sembarangan merupakan awal dari perubahan mewujudkan lingkungan yang bersih dan sehat. Sosialisasi tentang bahaya sampah menjadi sangat penting untuk membuka kesadaran masyarakat untuk mengenalkan kepada masyarakat tentang dampak negatif maupun positif yang berhubungan dengan sampah sehingga masyarakat tidak lagi membuang sampah sembarangan dan masyarakat mampu untuk memanfaatkan sampah menjadi barang yang ekonomis.
\end{abstract}

Kata Kunci : Penanggulangan sampah, perilaku hidup sehat, sampah rumah tangga

\section{PENDAHULUAN}

Keadaan Geografis

Desa Cibitung Kulon merupakan salah satu desa di wilayah Kecamatan Pamijahan Kabupaten Bogor dengan Luas Wilayah 201,3 Ha, diatas permukaan laut 520 - 550 meter, dan tingggi curah hujan $120 \mathrm{~m}^{3}$. Terdiri dari 3 (Tiga) Dusun dengan 8 Rukun Warga (RW), 21 Rukun Tetangga (RT).

Adapun perbatasan Desa Cibitung Kulon sebagai berikut:
Sebelah Utara: Desa Cibitung Wetan dan Desa Pamijahan

Sebelah Selatan: Desa Ciasihan

Sebelah Timur: Desa Gunung Sari

Sebelah Barat: Desa Cibunian dan Desa

Pura Sari Kecamatan Leuwiliang

Pada umumnya lahan yang terdapat di

Desa Cibitung Kulon digunakan secara Produktif dan hanya sedikit saja yang tidak dipergunakan. Hal ini menunjukan bahwa Kawasan Desa Cibitung Kulon memiliki 
Sumber Daya Alam yang memadai dan siap untuk diolah.

Tabel 1 Luas Wilayah Berdasarkan Fungsi Lahan

\begin{tabular}{|c|c|}
\hline Penggunaan Lahan & Luas \\
\hline $\begin{array}{l}\text { Perumahan / pemukiman } \\
\text { dan Pekarangan }\end{array}$ & $8,4 \mathrm{Ha}$ \\
\hline Sawah & $\begin{array}{l}163,48 \\
\mathrm{Ha}\end{array}$ \\
\hline Jalan & $0,5 \mathrm{Ha}$ \\
\hline Pemakaman / Kuburan & $1,3 \mathrm{Ha}$ \\
\hline Perkantoran & $\begin{array}{l}0,13 \\
\mathrm{Ha}\end{array}$ \\
\hline Lapangan Olah raga & $0,5 \mathrm{Ha}$ \\
\hline $\begin{array}{l}\text { Tanah / bangunan } \\
\text { Pendidikan }\end{array}$ & $0,7 \mathrm{Ha}$ \\
\hline Tanah / bangunan Pribadi & $\begin{array}{l}0,32 \\
\mathrm{Ha}\end{array}$ \\
\hline
\end{tabular}

\section{Sejarah Desa}

Sejarah nama "Cibitung Kulon" yaitu berasal dari sungai Cibitung yang sering dipergunakan untuk Kepentingan seharihari masyarakat sehingga masyarakat desa tidak kesulitan air untuk keperluan seharihari. Maka nama Desa Cibitung Kulon diambil dari kata Air dan Bambu dengan menggunakan bahasa sunda.

Ci berarti "Air" dan Bitung "Bambu". Pada tahun 1983 Cibitung Kulon dimekarkan menjadi 2 desa yaitu desa Cibitung Kulon dan Desa Cibitung Wetan. Pada saat itu pertimbangannya bahwa luas wilayah dan jumlah penduduk sudah saatnya untuk dimekarkan, dan untuk Desa Cibitung Kulon sebagai Desa Induk hanya memiliki jumlah luas wilayah 201,3 Ha.

\section{Kondisi Masyarakat}

Kondisi masyarakat berhubungan dengan suatu wilayah yang terdapat penduduk, tetapi keadaan penduduk tiap wilayah berbeda-beda. Hal ini disebabkan oleh berbeda kepadatan, sosial ekonomi, mata pencaharian, budaya dan karakternya. Berikut kondisi masyarakat Desa Cibitung Kulon.
Kondisi Sosial Budaya Desa

Tabel 3 Kondisi Sosial Budaya Desa

\begin{tabular}{|c|c|c|}
\hline No. & Uraian & Jumlah \\
\hline \multirow[t]{11}{*}{1} & Kependudukan & \\
\hline & A. Jumlah Penduduk (Jiwa) & 6.910 \\
\hline & B. Jumlah KK & 1.733 \\
\hline & C. Jumlah laki-laki & 3.545 \\
\hline & a. $0-15$ tahun & \\
\hline & b. $16-55$ tahun & \\
\hline & c. Diatas 55 tahun & \\
\hline & D.Jumlah perempuan & 3.365 \\
\hline & a. $0-15$ tahun & \\
\hline & b. $16-55$ tahun & \\
\hline & c. Diatas 55 tahun & \\
\hline \multirow[t]{8}{*}{2} & Tingkat Pendidikan & \\
\hline & A. Tidaktamat SD & 334 \\
\hline & B. SD & 1.035 \\
\hline & C. SLTP & 784 \\
\hline & D. SLTA & 436 \\
\hline & E. Akademi & 68 \\
\hline & F. Strata I & 36 \\
\hline & G. Strata 2 & 2 \\
\hline \multirow[t]{17}{*}{3} & Mata Pencaharian & \\
\hline & A. Buruh Tani & 538 \\
\hline & B. Petani & 781 \\
\hline & C. Tukang Ojek & 32 \\
\hline & D. Pedagang & 747 \\
\hline & E. Tukang bangunan & 113 \\
\hline & F. Tukang Las & 5 \\
\hline & G. Penjahit & 7 \\
\hline & H. PNS & 29 \\
\hline & I. Pensiunan & 11 \\
\hline & J. TNI/Polri & 3 \\
\hline & K. Swasta & 432 \\
\hline & L. Pengrajin & 15 \\
\hline & M. Sopir angkutan & 45 \\
\hline & N. Bengkel & 5 \\
\hline & O. Buruh Pabrik & 312 \\
\hline & P. Lain-lain & 934 \\
\hline \multirow[t]{7}{*}{4} & Agama & \\
\hline & A. Islam & 6.904 \\
\hline & B. Kristen & - \\
\hline & C. Protestan & \\
\hline & D. Katolik & - \\
\hline & E. Hindu & - \\
\hline & F. Budha & - \\
\hline
\end{tabular}

serta keamanan dan ketertiban di wilayah 
Desa Cibitung Kulon cukup aman terkendali. Dalam hal ini kehidupan politik warga masyarakat dapat disalurkan sesuai

\section{METODE PENGABDIAN}

Metode berasal dari bahasa Yunani yaitu methodos yaitu cara atau jalan menuju sesuatu dan merupakan kegiatan ilmiah yang berkaitan dengan fenomena-fenomena tertentu secara sistematis untuk memahami dan menyimpulkan objek yang diteliti.

Metode yang dimaksud disini yaitu methode pelaksanaan KKN yang tidak lain merupakan tindakan dari penelitian sebagai langkah awal me laksanakan KKN karena sebelum terjun kelapangan tentu saja perlu dilakukan beberapa penelitian untuk perumusan masalah dan penemuan solusi. Adapun methode- methode yang digunakan dalam pelaksanaan $\mathrm{KKN}$ Tematik Terintegrasi tersebut diantaranya yaitu metode etnografis dan studi kasus.

\section{Metode Etnografis}

Istilah etnografis berasal dari bahasa Yunani yaitu ethnos (bangsa) yang berarti orang dan graphein (menguaraikan), jadi dapat diartikan sebagai upaya mendeskripsikan budaya atau cara hidup orang-orang dalam suatu komunitas tertentu.

Metode etnografis yaitu metode yang digunakan untuk menginterpretasi dan mengukur budaya, kelompok sosial dan suatu sitem dalam masyarakat baik dari segi cara berfikir, adat, bahasa, kepercayaan atau pola dan tingkah laku hidup suatu masyarakat. Metode ini biasanya digunakan dan dilaksanakan dalam waktu yang cukup lama karena butuh proses dan fakta yang akurat bukan hanya perkiraan yang bisa dideskripsikan dalam kurun waktu yang singkat karena itulah butuh berbaur dan berada langsung dengan masyarakat. aspirasinya seiring dengan bergulirnya informasi dan banyaknya partai politik yang berkembang pada saat ini.

Disebut menggunakan metodhe ini karena setiap hasil dari penelitian selalu diuraikan dalam bentuk laporan yang bersifat deskriftif baik dari budaya, cara hidup dan prilaku masyarakat yang berada dilokasi sasaran pelaksaan KKN Tematik Terintegrasi ini, sehingga dengan mudah dapat ditarik kesimpulan dan gambaran mengenai pola hidup masyarakat tersebut.

\section{Studi Kasus}

Studi kasus merupakan salah satu metodologi penelitian yang bertujuan untuk mempelajari suatu peristiwa, keadaan atau perkembangan suatu fenomena terkait latar belakang keadaan sekarang dan suatu interaksi sosial baik individu, kelompok, lembaga, atau masyarakat. Studi kasus memerlukan keterampilan yang mantap karena harus berada dalam situasi senatural mungkin agar memperoleh data dan informasi yang akurat tanpa ada unsur manipulasi. Oleh karena itu perlu tahapan yang terprogram dan persiapan yang matang ketika hendak melaksanakannya. Studi kasus melibatkan investigasi kasus yang kemudian didefinisikan sebagai objek studi yang bersipat sederhana atau dibatasi, setelah kasus didefinisikan dengan jelas maka peneliti menyelid iki kasus atau objek tersebut secara mendalam dengan mengguakan beberapa metode pengumpulan data seperti wawancara, observasi lapangan dan dokumentasi.

\section{a. Wawancara}

Wawancara adalah percakapan dengan maksud tertentu. Percakapan itu dilakukan oleh dua pihak, yaitu pewawancara (interviewer) yang mengajukan pertanyaan dan yang 
diwawancarai (interviewee) yang memberikan jawaban atas pertanyaan itu. Maksud mengadakan wawancara, seperti ditegaskan oleh Lincoln dan Guba (1985: 266), antara lain : mengkontruksi mengenai orang, kejadian, kegiatan, organisasi, perasaan, motivasi, tuntutan, kepedulian, dan lain-lain. Teknik wawancara ini dilakukan dengan mengajukan beberapa pertanyaan ke beberapa narasumber di beberapa lokasi yang $\mathrm{m}$ ana obyek tersebut sedang di teliti oleh peserta KKN. Adapun narasumber yang dijadikan sumber informasi diantaranya yaitu bapak kepala desa, sekretaris dan stafstaf desa, struktur pemerintahan warga dari mulai RW, RT, kader posyandu, tokoh masyarakat, tokoh agama setempat berikut warga masyarakat sendiri. wawancara ini bertujuan untuk memperoleh data yang tidak didapatkan melalui observasi dan angket.

\section{b. Metode Observasi}

Observasi sebagai teknik pengumpulan data mempunyai ciri yang spesifik bila dibandingkan dengan teknik lain, yaitu wawancara dan kuesioner. Kalau wawancara dan kuesioner selalu berkomunikasi dengan orang, maka observasi tidak terbatas pada orang, tetapi juga obyek-obyek alam yang lain. Sutrisno Hadi (1986) mengemukakan bahwa, observasi merupakan suatu proses yang kompleks, suatu proses yang tersusun dari berbagai proses biologis dan psikologis. Dua diantara yang terpenting adalah proses-proses pengamatan dan ingatan. Dan dengan begitu, Penelitian ini akan menggunakan metode observasi untuk mengetahui secara langsung apa yang terdapat dilapangan.

\section{Survey Lapangan}

Survey merupakan salah satu metode yang digunakan untuk melihat langsung lokasi sasaran atau kegiatan yang dilaksanakan dilokasi sasaran sehingga mendapat informasi yang jelas, tepat dan benar serta nyata. Survey dilaksanakan untuk memberikan hasil yang pasti tentang objek yang dituju sehingga tidak ada keabstrakan dari informasi apapun.

Sasaran lokasi pelaksanaan KKN Tematik Terintegrasi untuk kelompok kami yaitu kelompok 39 diarahkan di Desa Cibitung Kulon Kecamatan Pamijahan yang awalnya masih bersifat abstrak mengenai lokasi sasaran yang tepat, oleh karena itu sebelum tanggal pelaksanaan KKN peserta KKN Tematik Terintegrasi dan DPL mengadakan survey terlebih dahulu ke pihak desa dan mengadakan wawancara singkat terkait lokasi sasaran sehingga diputuskan oleh pihak kades beserta peserta KKN Tematik Terintegrasi untuk fokus di RT 01 RW 05 Dari hasil survey dan wawancara terhadap warga masyarakat tersebut maka didapat gambaran awal keadaaan sasaran setempat.

\section{Metode Dokumentasi}

Metode dokumentasi adalah mencari data mengenai hal-hal atau variabel yang berupa catatan, transkip, buku, surat kabar, majalah, prasasti, notulen rapat, lengger, agenda, dan sebagainya. 


\section{REALISASI PROGRAM}

Selama pelaksanaan KKN 30 hari kurang lebih peserta KKN Tematik Teritegrasi Kelompok 26 melaksanakan rutinitas yang sebagian besar sudah terprogram, adapun rutinitas tersebut sebagaimana berikut ini:

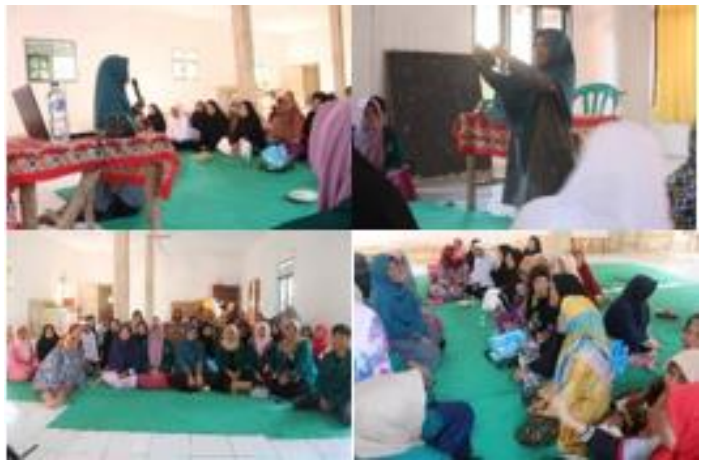

a. Penyuluhan mengenai Bahaya Sampah Kampung Ciaseupan Desa Cibitung Kulon

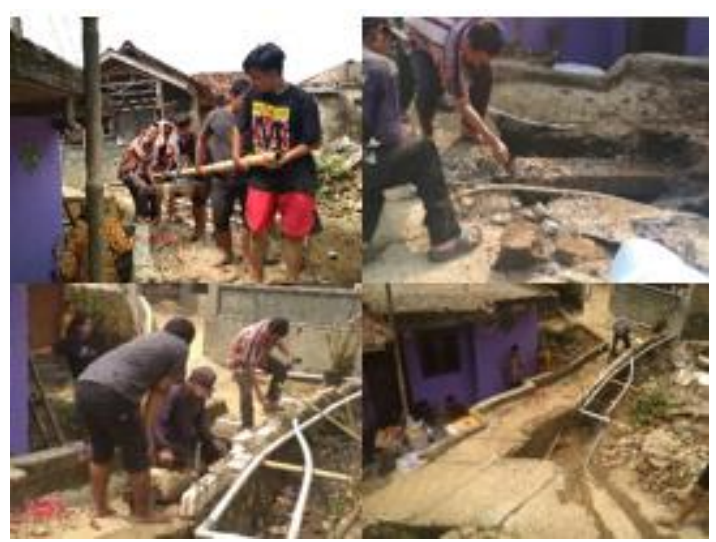

b. Penanggulangan Sampah dan Banjir

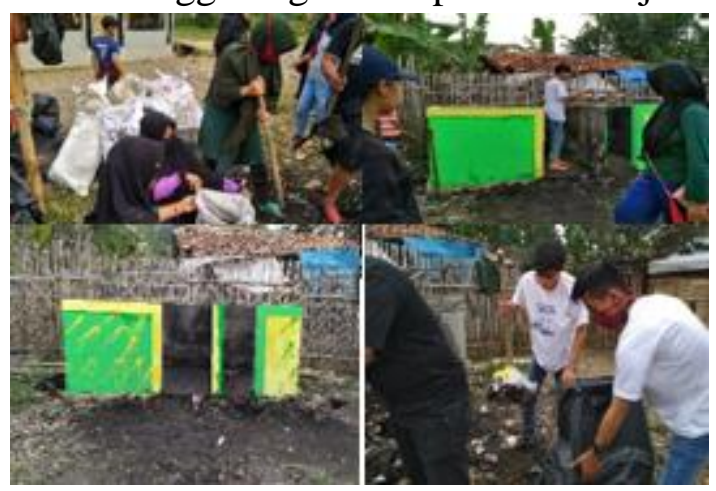

c. Pembaharuan Bak Sampah

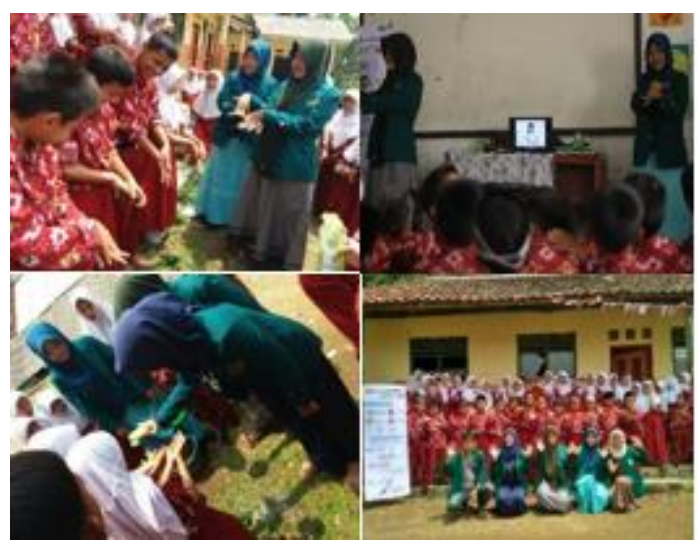

d. Penyuluhan Cuci Tangan Pakai Sabun

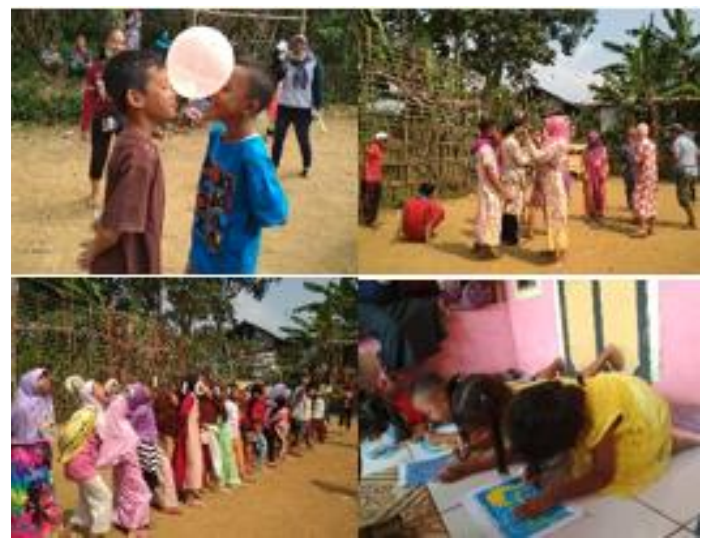

e. Perlombaan 17 Agustus

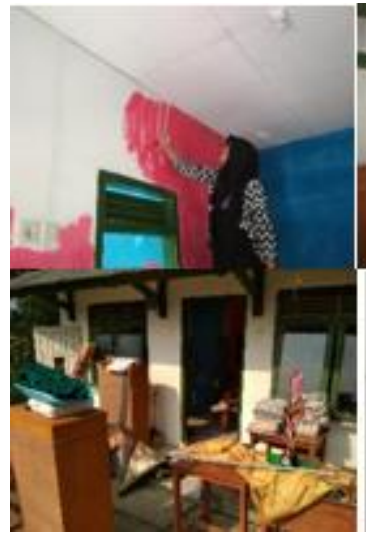

f. Pembaharuan

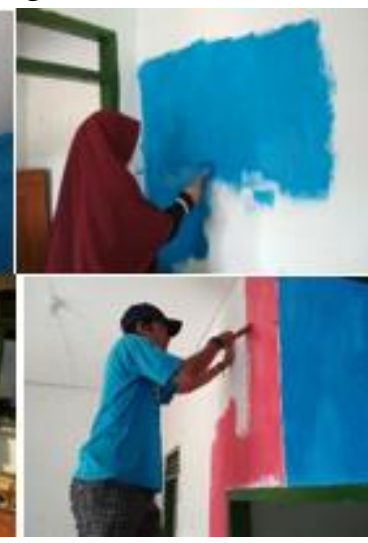

Posyandu dan 

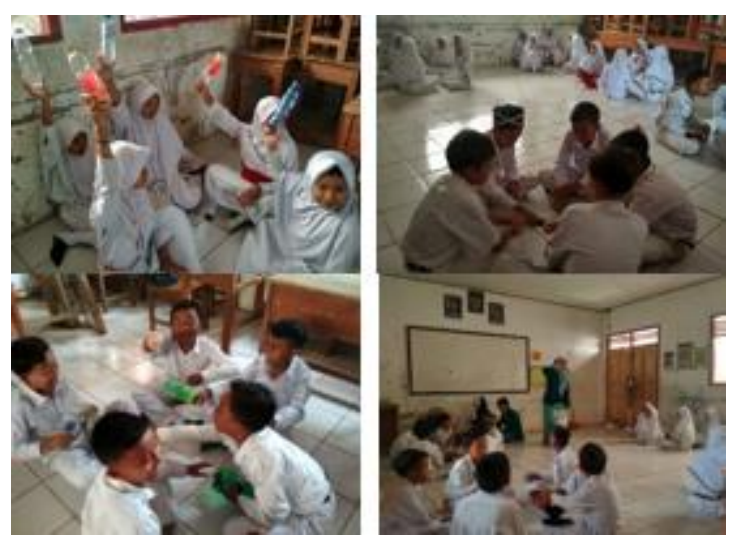

g. Pelatihan Menabung Sejak Dini dan Kerajinan Membuat Celengan dari Botol Bekas

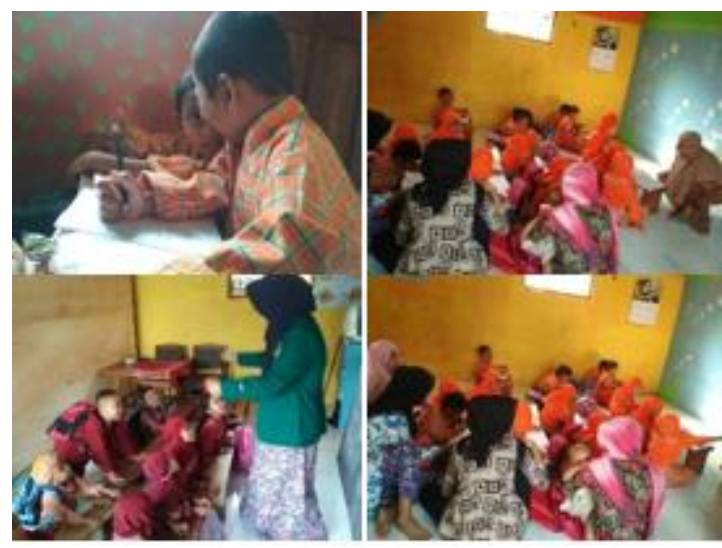

h. Membantu KBM di PAUD Nurul Falah dan MI Raudhatul Wildan

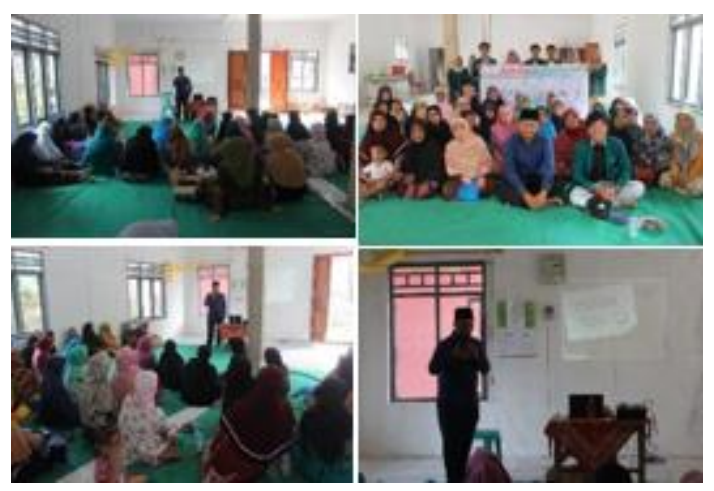

i. Workshop Kewirausahaan

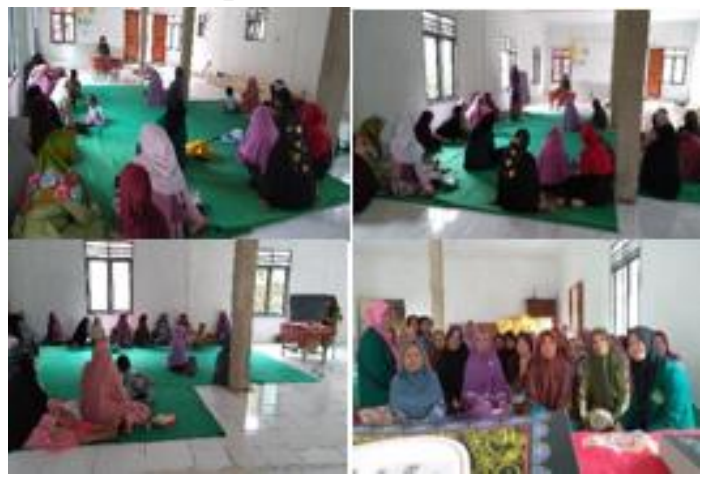

j. Pengajian Al-Qur'an khusus Ibu-Ibu

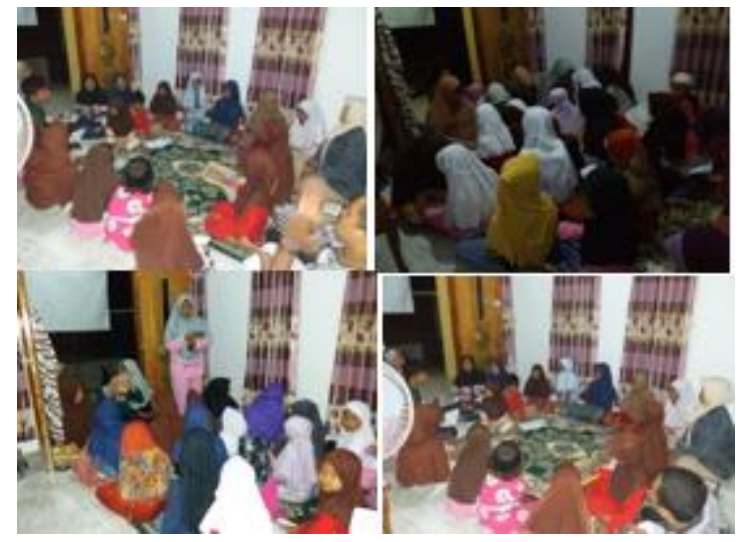

k. Mengajar Privat

\section{Dampak Bagi Masyarakat:}

a. Penyuluhan mengenai Bahaya Sampah Penyuluhan kesehatan mengenai bahaya sampah ini sangat bermanfaat bagi masyarakat agar masyarakat dapat tersadar dari kebiasaan perilaku yang selalu membuang sampah sembarangan mengakibatkan banyak hal seperti berdampak pada lingkungan sekitar dan menimbulkan berbagai macam penyakit. Dengan di laksanakannya penyuluhan ini masyarakat dapat merubah perilaku hidup yang lebih sehat dan bersih.

b. Penyuluhan Cuci Tangan Pakai Sabun Penyuluhan ini berdampak untuk membiasakan diri berperilaku hidup sehat dan bersih dan terbebas dari berbagai penyakit. Membiasakan hidup bersih dan sehat sejak dini akan melahirkan kebiasaan yang sehat demi terwujudnya generasi yang sehat dan baik.

c. Pelatihan Menabung sejak Dini

Menyadarkan anak-anak usia dini bahwa tabungan sangat berpotensi besar dalam kehidupan jangka panjang dari usia dini hingga dewasa, supaya dapat mencukupikebutuhan hidup tanpa harus meminjam kepada rentenir 
d. Workshop Kewirausahaan

Menyadarkan masyarakat bahwa berwirausaha itu sangat penting karena terbebas dari riba dan kelebihan timbangan.

e. Pendidikan

Setelah melakukan kegiatan perencanaan dan pelaksanaan dalam kegiatan Privat, Pemberdayaan dan perehabilitasi Taman baca dan Posyandu, ada beberapa dampak yang sangat berperan penting dalam kegiatan yang kami adakan. Diantaranya, ketika kami mengadakan kegiatan privat ternyata anak-anak siswa/i SD/MI sangat antusias sekali untuk mengikuti kegiatan privat tersebut. Selain itu masih ada beberapa

\section{SARAN}

\section{a. Bidang Pendidikan}

Demi keberlanjutan program yang telah dilaksanakan, kami berharap adanya pengelolaan khusus terhadap program pendidikan di desa cibitung kulon kampung ciaseupan agar menghasilkan anak-anak bangsa yang keratif, inovatif dan berkualitas bagi bangsa dan negara, dan adanya pengelolaan taman baca yang telah dibuat agar meningkatnya motivasi belajar serta wawasan ilmu pengetahuan. Teruntuk lembaga pendidikan formal di desa cibitung kulon, diharapkan lebih memperhatikan masyarakat setempat, dengan menggunakan sumber-sumber belajar yang baik dan benar Yang terpenting selalu adanya koordinasi antara pihak pendidik dengan wali murid agar pembelajaran lebih bisa diterima dan diterapkan dalam kehidupan.

\section{b. Bidang Kesehatan}

Demi berkelanjutan program yang telah dilaksanakan, kami berharap adanya diataranya yang minim akan pengetahuan dari bidang agama, sosial dan lain sebagainya. Setelah mereka mengikuti kegiatan privat, dampak yang telah kami rasakan terlihat jelas. Sedikit demi sedikit mereka mengetahui apa yang sebelumnya mereka tidak ketahui.

Selanjutnya, dampak setelah kita melakukan kegiatan pemberdayaan serta perehabilitasi Taman Baca dan Posyandu yaitu di antaranya semakin banyak minat untuk membaca di Taman Baca yang dikarenakan mungkin Taman Baca yang kami Rubah menjadi menarik dan memiliki beberapa Buku yang baru yang dapat dibaca menurut mereka.

pengelolaan khusus terhadap program kesehatan kampung Ciaseupan. Serta untuk masyarakat kampung Ciaseupan agar lebih menjaga lingkungan dan tidak merusak lingkungan dengan membuang sampah sembarangan. Kami berharap masyarakat kampung ciaseupan lebih memperluas pengetahuan kesehatannya dan lebih waspada terhadap penyakit menular yang pernah terjadi sebelumnya di wilayah kampung ciaseupan. Kami berharap setiap keluarga di kampung ciaseupan mampu menjaga kebersihan di rumahnya masingmasing, kemudian lingkungan sekitar rumah dan dan lingkungan seluruh kampung ciaseupan. Untuk masalah sampah kami berharap masyarakat lebih kreatif dan inovatif lagi dalam pengolahannya serta lebih bagus lagi dan bernilai ekonomis. Kami berharap masyarakat mengadakan kerja bakti seminggu sekali di kampung Ciaseupan karena kebersihan merupakan tanggung 
jawab bersama, bersih menjadikan seluruh masyarakat kampung ciaseupan menjadi sehat dan kebersihan juga sebagian dari iman.

\section{c. Bidang Agama}

1) Mengadakan kegiatan islami yang menarik seluruh minat masyarakat, tidak hanya kaum ibu-ibu akan tetapi seluruh masyarakat di kampung Ciaseupan sehingga seluruh warga dapat berpartisipasi dan memiliki motivasi yang lebih kuat dalam beribadah dengan sarana ibadah yang sudah cukup memadai, sehingga sarana ibadah tidak terbengkalai.

2) Mengadakan kegitan yang lebih menyentuh dan hati masyarakat dengan beberapa kegitan tidak hanya monoton dalam kegitan agama di Kampung Ciaseupan Desa Cibitung Kulon untuk mengetahui kompetensi masyarakat setempat dengan mengadakan acara yang menarik seperti Tabligh Akbar dan sebagainya.

\section{d. Bidang Teknik}

1) Dengan adanya $\mathrm{KKN}$ ini semoga Mahasiswa/Mahasiswi dapat berkembang dan lebih mempersiapkan segala sesuatunya lebih matang sebelum di lepas ke dunia kerja.

2) Kami harap dengan adanya program kegiatan yang telah kami selenggarakan dapat menjadi apresiasi warga masyarakat di Desa Cibitung Kulon. selain itu Produk yang telah kami sediakan dan diperbaharui bisa di implementasikan dalam kehidupan sehari-harinya.

\section{e. Bidang Ekonomi}

1) Memberikan fasilitas kepada warga Kp. Ciaseupan untuk membuat koperasi syariah agar menghindari terjadinya riba dan terbebas dari bank keliling (rentenir).

2) Memberikan ilmu pengetahuan kepada masyarakat Desa Cibitung Kulon tentang berwirausaha berbasis Syariah, agar masyarakat paham tentang wirausaha berbasis syariah yang terbebas dari riba.

3) Mendukung prekonomian Desa Cibitung Kulon yang kreatif dan inovatif dan memdaur ulang sampah menjadi barang yang dapat diperjualbelikan. 


\section{REFERENSI}

Hartono Rudi (2008), Ebook Penanganan dan Pengolahan Sampah

https://books.google.co.id/books?hl=id\&lr $=\& \mathrm{id}=$ OfOWCgAAQBAJ\&oi=fnd $\&$ $\mathrm{pg}=\mathrm{PP} 1 \& \mathrm{dq}=$ penanganan $+\mathrm{sampah}+\mathrm{r}$ umah+tangga\&ots $=0 \mathrm{oK} 34015$ e\&sig=xkVcYvOa0cdiwrdNkyM4n02BHs\&redir_esc $=y \# v=$ one page\&q=penanganan $\% 20$ sampah $\% 2$ 0rumah\%20tangga\&f=false

Lutfi, Muhammad. Hafidzhudin, Muhammad. Ramadhini, Aulia. Pemberdayaan Masyarakat Terhadap Lingkungan Serta Dalam Rangka Mengelola Bank Sampah untuk Inovasi Masyarakat Lebih Mudah Memilah Sampah. ABDIDOS, [S.1.], v. 2, n. 1, p. 73-84, Mar. 2018.
Sudiran F L (2005), Instrumen Sosial Masyarakat Karangmumus Kota Samarinda Dalam Penanganan Sampah Domestik, Jurnal Universitas 17 Agustus 1945, Samarinda

http://hubsasia.ui.ac.id/old/index.php/hubs asia/article/view/108/114

Wibowo Istiqomah (2009), Pola Perilaku Kebersihan: Studi Psikologi Lingkungan Tentang Penanggulangan Sampah Perkotaan, Jurnal Universitas Indonesia

http://repository.ui.ac.id/contents/koleksi/2 12803b30b2cbb66037fea8c077a9da4 599d4309f6.pdf 